\title{
ACUTE AND GHRONIC NON-TUBERCULOUS PYURIA IN CHILDREN
}

\author{
BY \\ A. VICTOR NEALE, M.D., M.R.C.P., \\ Physician to Out-patients, Children's Hospital, Birmingham.
}

Bacillus coli infection within the renal tract is of common occurrence in children and like many other disorders the disease may be recognized in an acute or chronic phase. Probably a large number of cases are overlooked, the general disturbance, unless severe, and the urinary abnormality clearing up under simple medicinal methods. Nevertheless there are several points of great importance to be considered in this group of diseases. It is not the writer's intention here to argue or to attempt to prove how the bacilli reach the renal tract initially. Suffice it to say that there are probably two important ways, an ascending urinary tract infection from the urethra or bladder, and by the hæmatogenous route. A lateral spread from such conditions as appendicitis or entero-colonic conditions is unlikely, although B.coli bacteriæmia or septicæmia may so arise and cause infection in the urinary tract. It has recently been shown that so-called catheter fever is due to actual invasion of the blood stream by coliform bacilli after slight urethral trauma. It is remarkable that many of the coliform bacilli possess unusual pathogenic powers when introduced into the urinary tract, and under certain conditions purulent discharge due to these bacteria may prove extremely resistant to treatment, a condition of chronic pyuria resulting.

The observations tendered in this paper are chiefly concerned with a clinical study of about one hundred and thirty cases of pyuria, some of the main questions under consideration being (a) does the so-called acute pyelitis cause any immediate or remote renal damage? (b) why does the pyuria become chronic in some patients? (c) what is the treatment of the different types of case?

During a period of five years (1924-29) one hundred and seventeen cases of pyelitis were admitted to the Children's Hospital, Birmingham. It should be remembered that this number of cases in no way indicates the frequency of the infection in children since many of the milder examples are satisfactorily treated in the out-patient department. Any case of persistent pyuria would necessarily be admitted for further detailed investigation. Therefore it is true that most of the cases studied in this paper have been patients who showed clinical evidence of severe general disorder associated with the urinary findings. Obviously such a large number of cases would show a wide variety of clinical symptoms. 
In infants the clinical aspect is that of a moderately severe illness often associated with marked pyrexia, and rapid loss in weight; and frequently preceded, accompanied or followed by such gastro-intestinal disorder as diarrhœa, vomiting, dehydration and ketosis. Often there is little to indicate the renal tract disorder, such conditions as meningism (especially seen in cases with very high temperature), twitchings and convulsions, and a bulging fontanelle attracting the clinician's attention to the nervous system, but in such cases the cerebro-spinal fluid is normal although its volume is increased. The pyuria in some instances would seem to appear intercurrently or to follow definite disease elsewhere, e.g., otitis media, bronchiolitis, gastro-enteritis ; and the clearing up of the original condition may not be followed by satisfactory clinical improvement. Sometimes abdominal distension and tenderness or definite loin pain may be detected. Vulval, scrotal or gluteal excoriation may be seen. In infancy therefore the examination of the urine may lead at once to a satisfactory diagnosis. In the earliest stages of some very acute cases the evidence of renal tract infection may be little but in a few days frank pyuria and bacilluria appear. Possibly this latter type of case is due to an actual blood-stream infection with the organism which soon becomes localized in the renal tract.

In the older child the symptomatology is more often directly referable to the urinary system, the complaint varying from enuresis to a severe general febrile disturbance with loin pain and tenderness, frequency of micturition, dysuria and opalescent hyperacid urine. In the charts the symptoms are recorded to illustrate the great variability in the clinical picture.

In the whole series of 117 patients the usual duration in hospital was two to four weeks, most cases clearing up quickly under medical treatment. Nine patients died and in each instance (as will be discussed later in greater detail) a more serious disease process was detected, seven showing suppurative pyelonephritis (one case complicated by thrombosis of the left renal vein), one infection of a congenital hydronephrosis and one pneumococcal meningitis. It is significant that eight of the fatal cases were under the age of one year, the youngest infant being only five weeks old. Even so, the mortality rate is low since forty-seven of the cases under treatment were less than two years of age and in the group of seventy cases over two years of age only one died, from suppurative pyelonephritis. Here therefore there is evidence that acute coliform infection may have more serious consequences in the infant.

An outline of the treatment afforded the cases while in hospital has been given by my senior colleague, Dr. K. D. Wilkinson ${ }^{1}$, and I shall not here further elaborate this. Certain points must be carefully considered, however, if adequate response to treatment is not observed. Persistent pyuria occurring in some of the cases in this series has been due to (a) suppurative pyelonephritis, (b) infection associated with a congenital malformation in the urinary tract, (c) calculus formation, or (d) residual infection of the posterior urethra or the base of the bladder; and one or more of these conditions may co-exist. A more detailed study and consideration of these resistant cases is given later. 
The acute case.-Is there any evidence of immediate or remote renal damage in the patient who responds quickly to treatment? In only one or two cases has any visible cedema been seen and although in some of the very young children occasional convulsions and twitchings have been seen these latter signs have usually been associated with high temperature and meningism and therefore of doubtful significance as regards uræmia. The urinary findings would not lead one to suspect true nephritis - the albumin content is usually small, casts are nearly always absent although a few red blood cells may appear, and polymorphonuclear leucocytes are in abundance together with the infecting coliform bacilli. The volume of the urine may be normal or diminished in high pyrexia. No significant elevation of the blood pressure has been found. An examination of the blood has been made in some of the patients at intervals throughout the illness and the following two cases illustrate the usual results.

TABLE 1.

Showing BLOod-URea figures in aCUTE AND CUREd STAGeS of CASES OF ACUTE PYelitis.

\begin{tabular}{|c|c|c|c|c|c|c|}
\hline \multirow{2}{*}{$\begin{array}{c}\text { Case } \\
\text { No. }\end{array}$} & \multicolumn{4}{|c|}{ Acute stage } & \multicolumn{2}{|c|}{ Cured stage } \\
\hline & & Urine & & Blood urea & Blood urea & Urine \\
\hline 1 & $\begin{array}{c}\text { alb. } \\
\text { Present }\end{array}$ & $\begin{array}{c}\text { pus } \\
\text { Present }\end{array}$ & $\begin{array}{l}\text { casts } \\
\text { Absent }\end{array}$ & $\underset{41 \cdot 0}{\operatorname{mgrm} . \%}$ & mgrm. \% & Normol \\
\hline 2 & ," & , & , & $27 \cdot 0$ & - & , \\
\hline 3 & , & , & , & $33 \cdot 0$ & $32 \cdot 0$ & $"$ \\
\hline 4 & , & , & , & $72 \cdot 0$ & $33 \cdot 0$ & , \\
\hline 5 & , & , & , & $31 \cdot 0$ & - & , \\
\hline 6 & , & , & , & $38 \cdot 0$ & - & , \\
\hline 7 & , & , & Present & $38 \cdot 0$ & - & , \\
\hline 8 & , & ," & Absent & $72 \cdot 0$ & $26 \cdot 0$ & , \\
\hline 9 & , & , & , & $42 \cdot 0$ & $35 \cdot 0$ & ", \\
\hline 10 & , & , & , & $51 \cdot 0$ & $27 \cdot 0$ & $"$ \\
\hline 11 & , & , & , & $42 \cdot 0$ & $21 \cdot 0$ & , \\
\hline 12 & , & , & , & $21 \cdot 0$ & 一 & , \\
\hline 13 & , & , & , & $70 \cdot 0$ & $30 \cdot 0$ & , \\
\hline 14 & , & , & , & $75 \cdot 0$ & $35 \cdot 0$ & , \\
\hline
\end{tabular}

Case 13.-G. S., girl, aged 11 years. Admitted June 20th, 1930. She had had pain in the back for 8 days, with high fever, frequency of micturition and tenderness in the loins. Diagnosis : acute pyelitis. Treatment by alkalis throughout illness.

On admission : urine acid, albumin + , pus cells +++ , B. coli ++ , no blood, no casts. Blood urea, 70 mgrm. per cent.

Five days later the condition of the urine was unaltered, and the blood urea was 69 mgrm. per cent. By July 2nd the urine was alkaline, and showed a trace of albumin but no pus : B. coli were still present. The blood urea had fallen to $51 \mathrm{mgrm}$. per cent. The blood pressure was 95/70. On July 9 th the urine was normal, and the blood urea 41 mgrm. per cent. On July 17 th the urine was normal, the Calvert test $2 \cdot 7$ per cent. and urea 0.8 per cent. The blood urea was $30 \mathrm{mgrm}$. per cent. Treatment was abandoned. Recovered.

Case 14.-A. R., girl, aged $1 \frac{1}{2}$ years. She had been ill for a few days, with vomiting, drowsiness and high fever $\left(104^{\circ}\right)$. Diagnosis: acute pyelitis. Treatiment throughout by alkalies and caprokol. 
On admission (June 26th, 1930) the urine was acid and showed much pus and albumin, and was heavily infected with B. coli. No casts or blood present. The blood urea was $\mathbf{7 4 . 5}$ mgrm. per cent. By July 19th the urine was neutral and still showed a little pus with a trace of albumin. On the 28th the urine was normal, and the blood urea $35 \mathrm{mgrm}$. per cent. Recovered.

The blood urea is seen to be raised soon after the onset of the disease and this nitrogen retention indicates that there is some temporary renal impairment. No casts were found in the urine of either of these two cases and a few cases which have shown occasional casts, no higher, and often lower blood-urea figures have been obtained. It must be admitted, therefore, that some renal damage may occur even in the absence of casts, but this is only temporary and rapidly disappears as the pyuria clears. Table 1 shows a series of cases in which the blood urea was determined in the acute and in the cured stages of the illness.

In each instance the general clinical condition, the urinary and the blood findings indicate a total cessation of the morbid processes in the renal tract and complete recovery can be confidently anticipated. One case of acute pyelitis, two weeks after complete recovery from this disease, died from other causes. A careful examination of the kidneys, ureters and bladder showed a perfectly normal appearance.

Fatal cases. - The acute cases which did not respond to treatment and which ended fatally after a few weeks of illness were examined in detail and in each instance very severe renal disease was found. In most instances suppuration in the kidney substance with considerable destruction of tissue was present or the initial condition was congenital hydro-nephrosis with atrophy of the renal cortex and acute suppuration added.

\section{Pathological reports of fatal cases.}

Case 15.-A. R., aged 8 months, female. Had pyuria since aged 10 weeks. Urine con. tained albumin, pus and B. coli but no blood or casts.

Both kidneys enlarged with numerous irregular swellings on the surface. Each showed many small suppurative foci in the medulla and cortex and a large amount of purulent exudate in the pelvis. The mucosa of the whole urinary tract was congested. Microscopically an intense degree of acute inflammatory cellular infiltration was seen throughout the kidney tissue with abscess formation. The collecting tubules were packed with pus cells and similarly the pelvic mucosa. There is a remarkable absence of change in the glomeruli and excreting tubule epithelium.

Case 16.-B. C., aged 1 year and 4 months, female. Ill 3 weeks. Urine showed albumin, pus, and B. coli.

The kidneys showed thickening and purulent inflammation of the pelves, and many foci of acute inflammatory necrosis and early suppuration in the renal substance.

Case 17.-E. B., aged 3 months, female. Ill 10 days. Albumin, pus, and B. coli present in urine.

The kidneys were enlarged, softened and the pelvic mucosa thickened. Microscopically a considerable degree of hyperæmia and œedema of the pelvic mucosa with frankly suppurative process in the collecting tubules, many of which appear to be blocked up with the exudate, the secreting epithelium and glomeruli showing only slight changes.

Case 18.-B. B., aged 10 months. Ill 5 weeks. Urine showed albumin, pus and B. coli.

The left kidney was twice the normal size, deep red colour with thrombosis of the renal vein. Both renal pelves thickened, dilated and purulent.

Case 19.-B. S., aged 2 months, male. Ill 8 weeks. Albumin, pus and B. coli present in urine. Each kidney enlarged and extremely dilated pelves and narrowed cortex with gross suppuration therein. Ureters also show irregular dilatation. Bladder normal, 
These notes concerning fatal acute cases indicate the severity and nature of the lesions found therein. A suppurative process extending into the renal substance renders the prognosis bad, but the only significant differential clinical features indicating this extension of the disease are diminished excretion of urine, persistence of the pyuria, and in some cases a continued severe febrile disturbance with progressive physical deterioration.

\section{End results in fifty-six non-fatal cases.}

In order to determine the ultimate conditions present in children who have been under observation and treatment for pyuria, fifty-six patients have been carefully re-examined, especially concerning the general physical progress, the state of the renal tract, the recurrence or persistence of infective pyuria and the cardio-vascular condition. In many instances two or three years had clapsed between the first record and the recent record.

Recovered cases.-Forty-nine of these children were remarkably well when re-examined two or more years after treatment for clinically acute pyelitis. The very satisfactory general impression obtained when examining these children is confirmed by careful investigation in each individual case and in no instance could any physical or mental retardation be detected. The urine, renal function and blood urea is normal in each child. This is confirmatory of the hopeful conditions noted above, when it was shown that in all cases in which the pyuria rapidly cleared, any initial renal impairment was corrected and no later effects on the kidney tissue was demonstrable. In response to enquiries it was found that no child (among the whole series originally treated) had died from renal disease, although four were dead of diphtheria and pneumonia.

Persistent cases.-In the fifty-six children re-examined, persistent pyuria was detected in seven instances whose clinical details are given below. Consideration of each case reveals an interesting reason for the chronicity of the infection.

Case 20.-J. Y., male, aged $7 \frac{1}{2}$ years. General condition good. No cardio-vascular changes. No retinal signs. B.P. 100/80. No bone changes. Blood urea 24.8. Has had heavy pyuria with bacillus coli for several years with practically no symptoms. Has been under careful medical control at home.

Intravenous urography shows large dilated kidney pelves, most probably infected con. gential hydronephrosis (bilateral). There is nothing to indicate bladder disease.

Case 21.-I. G., female, aged $6 \frac{1}{2}$ years. General condition good. No cardio-vascular changes. No abnormal retinal signs. B.P. 110/90. Blood urea $30 \cdot 0$ Only symptom is occasional dysuria. Has had intermittent medical treatment. Urine always shows a moderate amount of pus and numerous bacillus coli.

Intravenous urography shows a marked deformity of the right kidney pelvis. Cystoscopy shows a little congestion of the bladder mucosa.

Case 22.-E. S., female, aged $2 \frac{1}{2}$ years. General condition good. No signs or symptoms but urine constantly shows large amounts of pus and bacillus coli. Blood urea 45•0. No renal swellings palpable and cystoscopy shows a normal bladder. No urographic examination was possible but almost certainly a congenital defect is present in one or both kidneys, allowing persistence of the infection, 
Case 23.-L. W., female, aged 14 years. General condition poor. Anæmia and sallow skin. In 1927 a right pyelogram showed a large dilated right renal pelvis; the bladder was normal. The urine was highly purulent and infected with bacillus coli. Right nephrectomy was performed and the excised kidney showed a very large dilated infected pelvis with atrophy of the renal substance. In 1930 the pyuria and bacilluria are still heavy and there are pain and tenderness and a palpable renal swelling in the left loin. The bladder is normal. Blood urea 56.0. B.P. $110 / 85$. Headaches. Retinæ normal. This child most probably had bilateral congenital renal malformations which became infected with bacillus coli which persisted. A right pyonephrosis was demonstrated in 1927 and excised and in 1930 a similar condition is detectable in the left.

Case 24.-H. M., female, aged $7 \frac{1}{2}$ years. General condition poor; small pale child. In 1928 heavy pyuria detected. Bladder normal. Pyelography revealed a large dilated right kidney and ureter with purulent exudate escaping into the bladder. Medicinal treatment and repeated lavage of the diseased ureter and kidney with 5 per cent. collargol failed to clear up the bacillus coli infection. In 1930 the health was poor and the pyuria still marked.

Case 25.-A. A., female, aged $7 \frac{3}{4}$ years. Good general condition. Blood urea 39.0. B.P. 110/90. Pyuria known to exist since 1929.

Intravenous urogram shows a dilatation of the left renal pelvis and a small calculus at the pelvi-ureteral junction.

Case 26.-J. E., female, aged 8 years. General condition very poor. Blood urea 78.0. B.P. 130/95. Polyuria. Specific gravity of urine 1005. Heavy pyuria has persisted for at least three years although practically no urinary symptoms are present. In 1928 the kidneys were examined at operation and the right renal pelvis was found to be markedly dilated, without ureteral dilatation. Also the left kidney was similarly affected but to a lesser degree. This child has therefore chronic infection of bilateral congenital hydronephrosis. There is evidence of advancing renal insufficiency owing to gradual destruction of kidney tissue.

The outstanding point in each case is the presence of some anatomical defect in the renal tract, and this is almost certainly the reason why the infection persists. One girl showed an occasional simple bacilluria and the urethral examination revealed an inflamed mucosa, the renal tract being normal otherwise.

For comparison with the above cases the following are instructive.

Case 27.-D.T., female, aged 16. In 1926 this girl had frequency of micturition, with pain in the left iliac fossa, dysuria and heavy pyuria. This persisted for three years and in 1929 the left kidney and ureter were dissected out and showed a bacillus coli infection of a congenital dilatation of kidney pelvis and ureter as far as the bladder. The right kidney and ureter and the bladder were anatomically normal. The pyuria rapidly cleared and the child's present condition is excellent; weighs 7 stones, blood urea normal and no urinary disorder.

Case 28.-C. T., male, aged 13 years. In 1926 a history of occasional pain in the left loin, vomiting, pyrexia was obtained. The boy appeared ill, was pale and had furred tongue. Physical examination showed a tender soft palpable renal swelling on the left side. Urine acid, albumin present, large amount of pus and bacillus coli.

Operation was performed by Mr. B. Goodwin. The capsule of the left kidney stripped away and a large infected hydronephrotic kidney removed. The ureter below the pelvi-ureteral junction appeared normal and the right renal tract was normal. Within a week the urine was perfectly clear and rapid general improvement had taken place.

Examination of the excised kidney showed a very dilated renal pelvis and an atrophied renal cortex. There was no apparent organic ureteral stricture and no calculi were present. Microscopically a simple pyogenic infection was demonstrated.

In 1930 this boy was re-examined. His general condition is excellent, the cardio-vascular system and renal function is normal, his urine quite clear and sterile and the operation scar perfectly healed.

Sufficient instances of chronic pyuria in children have now been observed to obtain information concerning the progression of the disease. The con- 
dition may be detected at the onset, in which case the clinical picture in no way differs from ordinary acute pyelitis. In many cases, however, the disease has been established a variable period of time when first recognized. There may be no symptoms but in most cases one or more complaints are made such as intermittent loin or ureteric pain, enuresis, polyuria or febrile attacks. Many cases, however, remain afebrile for long periods. The pyuria will be detected in some instances on a routine examination of the urine. The frequent absence

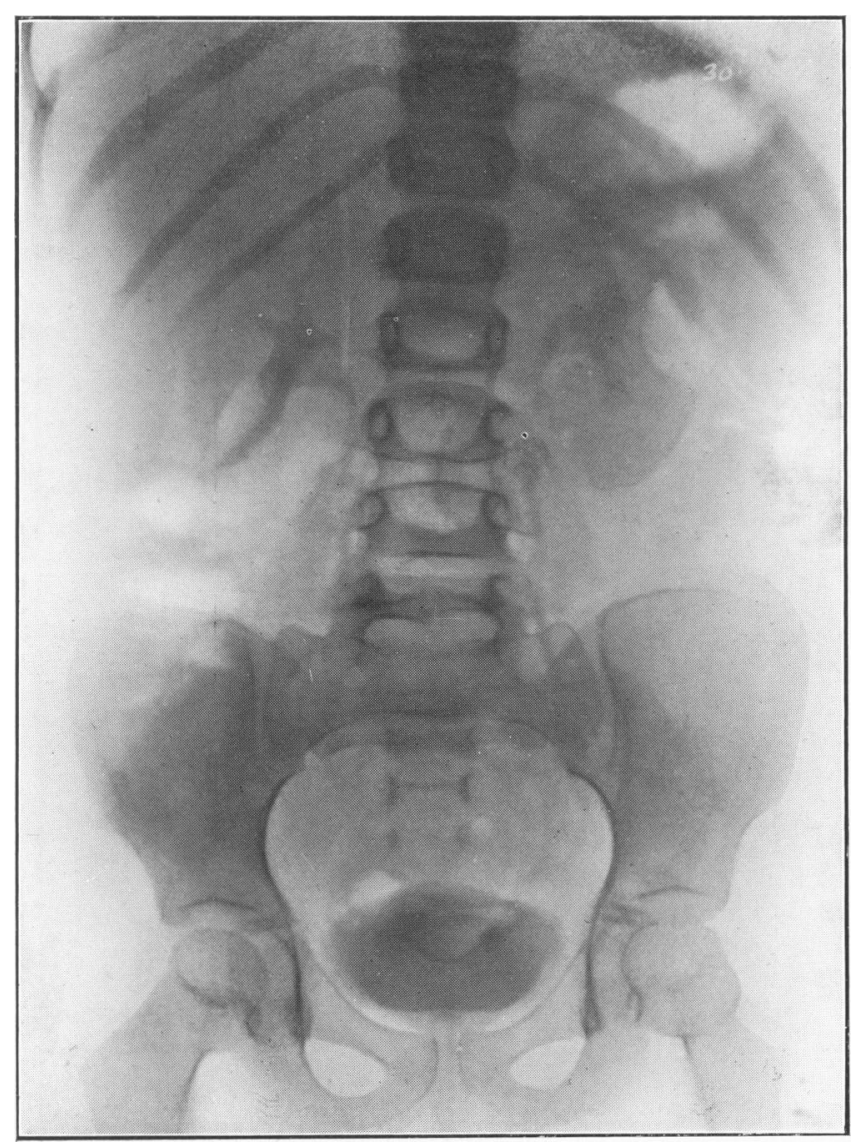

Fı. 1. Case (i. B., female aged 6 years. Normal child. Urogram .... showing normal urinary tract. (1 hour).

of any general disturbance perhaps for some years is rather remarkable. The benign nature of the general effect is more evident in the cases where the pyuria is due to unilateral renal and ureteric disease, e.g., Cases 20 and 21 above; and the physical effects of the chronic infection are more marked in cases showing bilateral renal tract infection, e.g., Cases 23 and 26. The cases of unilateral infection may undoubtedly continue for many years and the renal enlargement reach a considerable size-no doubt many of the cases of $\mathrm{B}$. coli pyonephorsis and pyo-ureter detected in young adults have arisen in childhood, the chronic 
infection arising in a congenital malformation in the upper urinary tract. Provided no acute spread of the suppurative process into the renal substance or sudden dispersion of the infection throughout the renal system takes place, no untoward symptoms occur. If, on the other hand, either through intercurrent illness or otherwise, acute pyelonephritis with intra-renal suppuration supervenes, rapid progress of the disease appears and death from uræmia and toxæmia is usual. When one kidney is normal, anatomically and otherwise,

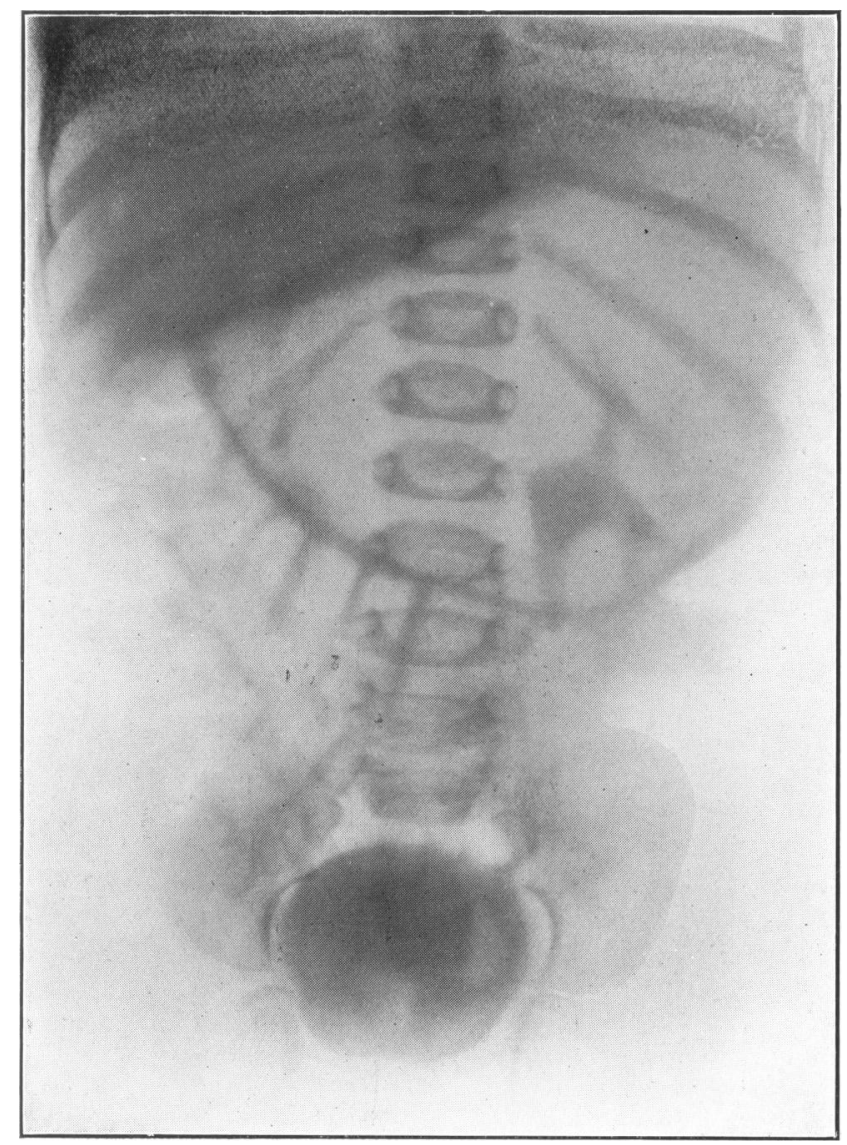

Fic. 2. Case D. C., male aged 6 months. Chronic pyuria. Intravenous urogram showing dilated left renal pelvis. $\varepsilon\left(\frac{8}{4}\right.$ hour $)$.

considerable hyperplasia can occur to compensate for the gradual destruction of its fellow and consequently renal insufficiency remains absent. On the contrary, where both kidneys are diseased, a slow progressive deterioration is evident and gradually nitrogen retention occurs, e.g., in Cases 23, 26 and 22 where the blood urea has reached 56, 78 and $45 \mathrm{mgrm}$. per cent respectively. Cardio-vascular changes may appear but are never prominent even in the advanced cases and retinal degeneration is not seen. In the final stages, 
which may be several years after the onset of the chronic infection, uræmic manifestations appear and death supervenes rapidly. After death extraordinary deformities in the renal tract are often found, with greatly dilated renal pelves showing gross suppuration and a mere shell of renal secretory tissue left. A remarkable feature in the disease is the postponement of any serious renal failure until so little kidney tissue remains. In certain respects the clinical course strongly resembles that of true congenital cystic disease

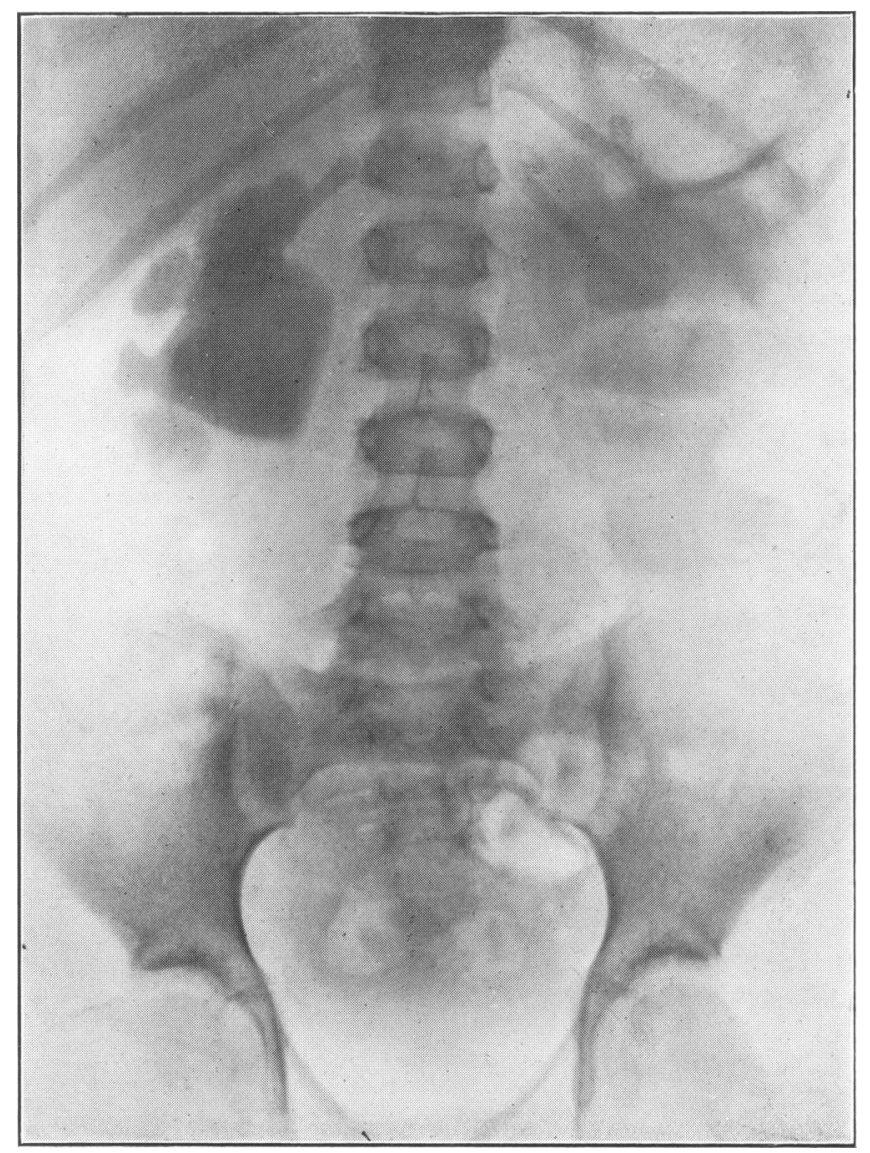

Fic. 3. Case J. Y., male aged 4 ł years. Chronic pyuria. Urogram showing dilatation of the renal pelves. Double pyo nephrosis. (2t hours.)

of the kidneys, another condition in which symptoms are often absent until an extraordinarily small amount of functionable kidney tissue is left, and where cardio-vascular and retinal changes are minimal and uræmia appears rapidly as a terminal event.

The complete investigation of the patient suffering from chronic pyuria is obviously of great importance in order to determine a.ccurately the reason for persistence of the disease. No case should be allowed to drift along in the 
hope of improvement by ordinary medicinal means. No degree of alkalinization of the urine or the use of urinary antiseptics is likely to be of any curative value in an infection associated with congenital deformity of the urinary tract. The recognition of this fact is highly important. Congenital malformations occurring in the kidneys and ureter are no doubt of greater frequency than is generally believed. In the course of a hundred consecutive necropsies in children congenital hydronephrosis of variable degree with or without hydro-

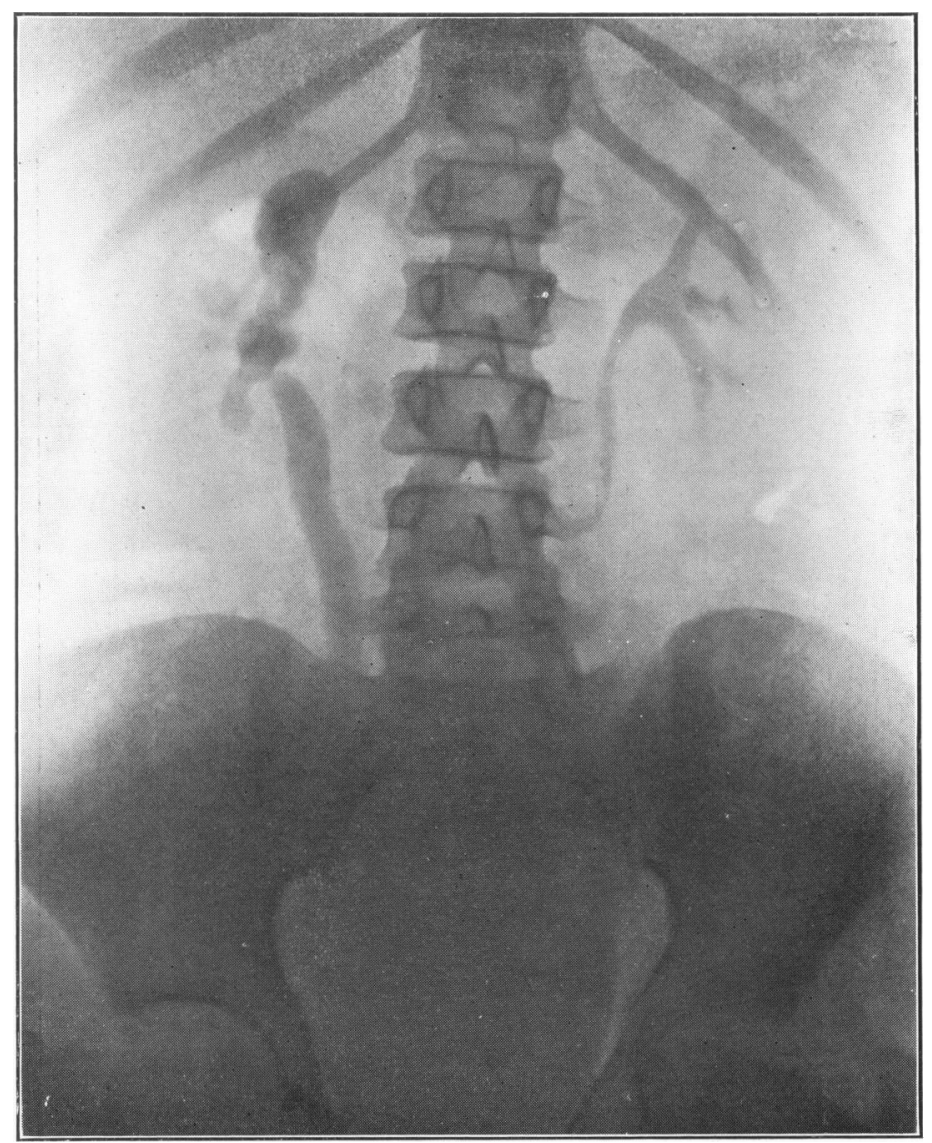

FIt, 4. Case L. 1., female aged 9 years. Chronic pyuria. Intravenous urogram showing disease in the right renal tract and a calculus in the right renal pelvis.

ureter, unilateral or bilateral, was found in five or six cases. In most instances no obstructive factor can be found to account for the dilatations and deformities, although in some instances an obvious narrowing in a part of the ureter is detected. Hurst ${ }^{6}$ has suggested that such uretero-pelvic dilatation may arise through achalasia of the uretero-vesical sphincter. It is very probable that great interference with the normal pelvi-ureteral peristaltic action takes place when the anatomical outline is distorted and thus stasis is likely to occur which 
is doubtless an important factor in preventing adequate power to eliminate infective material. It is therefore necessary to examine each patient for urinary tract malformations.

There are certain difficulties in applying the usual surgical procedures in investigating children. Cystoscopy usually presents no difficulties, but pyelography by ureteral catheterization may be extremely difficult or impossibie

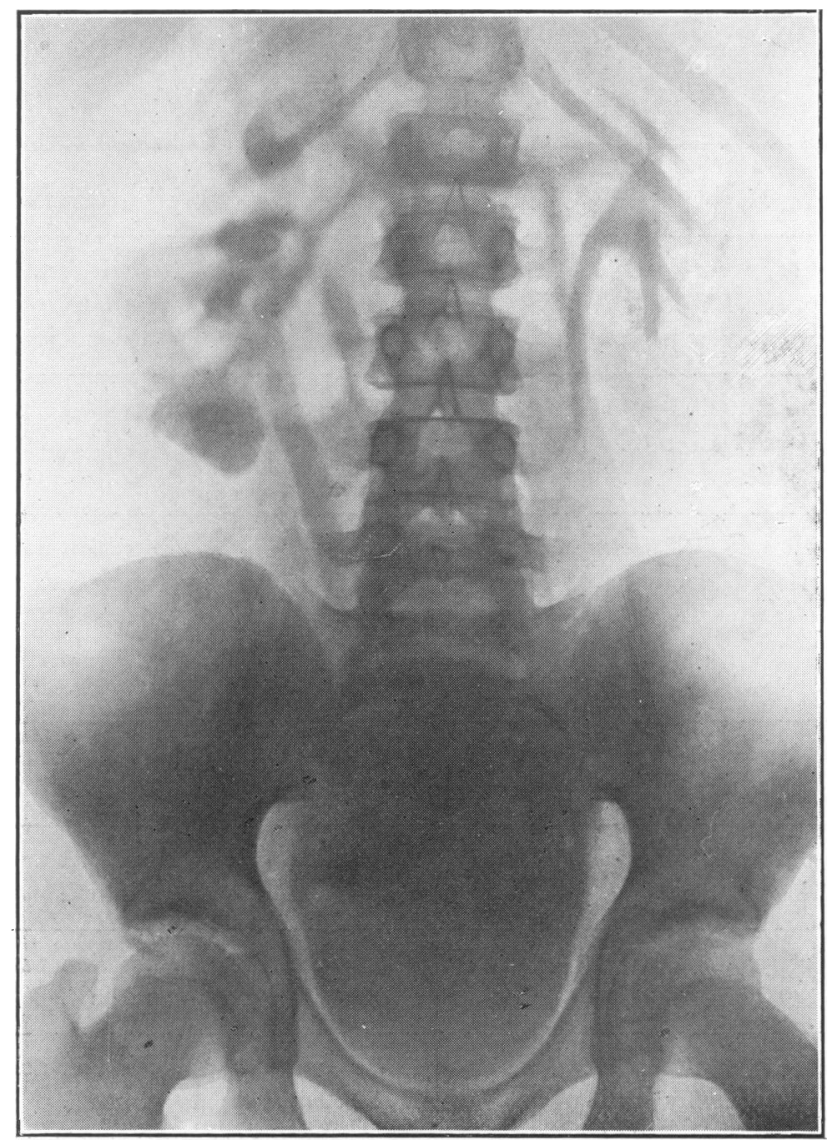

Fig, 5. Case L. L., female aged 9 years. Chronic pyuria. Intravenous urogram showing disease in the right upper renal tract. 2nd. test after operation for removal of calculus.

to carry out, if any serious degree of ureteral narrowing is present. The cystogram is useful occasionally, and ureteral reflux is shown in some abnormal conditions of the tract, but distortions and dilatations of the upper parts of the ureter and renal pelves are not shown.

By the use of intravenous injection of uroselectan (a pyridine compound containing 40 per cent. of organically combined iodine) followed by radiography, a very useful method of investigating the anatomy of the renal tract in 
children is now available. This substance which is opaque to X-rays, and practically non-toxic, is rapidly eliminated by the kidneys if advanced renal impairment is not present. Normally it appears in the bladder in about ten minutes after the intravenous injection, and very soon the renal pelves, ureters and bladder become distinctly outlined.

TABLE 2.

Cured cases investigated by URography.

\begin{tabular}{|c|c|c|c|c|c|c|c|c|}
\hline Date & Case No. & Age & Sex & History & Blood & Calvert test & Urogram & Remarks \\
\hline 1930 & A. D. & 10 & F & $\begin{array}{l}\text { Acute pyelitis with } \\
\text { pyuria } 1927 \text {. Cured } \\
\text { after a few weeks. }\end{array}$ & $\begin{array}{l}\text { Urea } 36 \\
\text { U.Ac. } 2 \cdot 7\end{array}$ & $\begin{array}{l}\text { A } 290 \mathrm{c.cm} .4 \cdot 4 \% \\
\text { B } 220 \mathrm{c.cm} .1 \cdot 5 \%\end{array}$ & $\begin{array}{l}\text { No calculus. Excre- } \\
\text { tion rate normal. } \\
\text { Tract normal. }\end{array}$ & $\begin{array}{l}\text { No renal tract de- } \\
\text { fects. Pyelitis } \\
\text { cured. }\end{array}$ \\
\hline 1930 & H. P. & 9 & $\mathbf{F}$ & $\begin{array}{l}\text { Pyelitis 1925. Pyuria } \\
\text { cleared in a few } \\
\text { weeks. }\end{array}$ & $\begin{array}{l}\text { Urea } 35 \\
\text { U.Ac. } 2 \cdot 7\end{array}$ & $\begin{array}{l}\text { A } 270 \mathrm{c.cm} .4 \cdot 6 \% \\
\text { B } 375 \mathrm{c.cm} .1 \cdot 2 \%\end{array}$ & $\begin{array}{l}\text { Excretion normal. } \\
\text { Tract normal. }\end{array}$ & ditto \\
\hline 1930 & L. M. & $14 \frac{1}{2}$ & $\mathbf{F}$ & $\begin{array}{l}\text { Pyelitis 1927. Pyuria } \\
\text { cleared. Bacilluria. }\end{array}$ & Urea 30 & 一 & $\begin{array}{c}\text { Excretion and tract } \\
\text { normal. Cystoscopy } \\
\text { shows a few in- } \\
\text { flamed urethral } \\
\text { glands. }\end{array}$ & ditto \\
\hline 1930 & G. B. & 6 & $\mathbf{M}$ & No disease. & Urea 30 & 一 & $\begin{array}{l}\text { Excretion and tract } \\
\text { normal. }\end{array}$ & \\
\hline 1930 & D. T. & 9 & F & $\begin{array}{l}\text { Acute pyelitis. Pyuria } \\
\text { clear in } 2 \text { weeks. }\end{array}$ & Urea 39 & $\begin{array}{l}\text { A } 380 \text { c.cm. } 3 \cdot 2 \% \\
\text { B } 480 \text { c.cm. } 0 \cdot 9 \%\end{array}$ & $\begin{array}{l}\text { Excretion and tract } \\
\text { normal. }\end{array}$ & ditto \\
\hline 1930 & D. L. & 9 & $\mathbf{F}$ & Acute pyelitis, cured. & Urea 38 & $\begin{array}{l}\text { A } 235 \text { c.cm. } 4 \cdot 2 \% \\
\text { B } 620 \text { c.cm. } 0 \cdot 6 \%\end{array}$ & $\begin{array}{l}\text { Excretion and tract } \\
\text { normal. }\end{array}$ & ditto \\
\hline 1930 & 13 & 11 & $\mathbf{F}$ & $\begin{array}{l}\text { Acute pyelitis } 1929 . \\
\text { Cured in } 2 \text { weeks. }\end{array}$ & Urea 31 & $\begin{array}{l}\text { A } 540 \text { c.cm. } 2 \cdot 7 \% \\
\text { B } 330 \text { c.cm. } 0 \cdot 8 \%\end{array}$ & $\begin{array}{l}\text { Excretion and tract } \\
\text { normal. }\end{array}$ & ditto \\
\hline 1930 & J. R. & 8 & F & $\begin{array}{l}\text { Acute pyuria. Cured } \\
\text { in } 1 \text { week. }\end{array}$ & Normal. & $\begin{array}{l}\text { A } 325 \text { c.cm. } 3 \cdot 2 \% \\
\text { B } 660 \text { c.cm. } 0 \cdot 6 \%\end{array}$ & $\begin{array}{l}\text { Excretion and tract } \\
\text { normal. }\end{array}$ & ditto \\
\hline 1930 & J. E. P. & $6 \frac{1}{2}$ & $\mathbf{F}$ & $\begin{array}{l}\text { Acute pyuria. Cleared } \\
\text { in } 2 \text { weeks. }\end{array}$ & Normal. & 一 & $\begin{array}{l}\text { Excretion and tract } \\
\text { normal. }\end{array}$ & ditto \\
\hline
\end{tabular}

In order to demonstrate the absence of any defective mechanism or deformity in the renal tract in cases of acute pyuria which rapidly clears up after ordinary medicinal treatment, a series were examined by the urographic method and the detajls are given in Table 2.

A number of children with chronic pyuria have been similarly examined by intravenous urography and Table 3 shows the results. In each case a 
deformity in the renal tract is present. In two patients Cases 25 and L. L. calculus formation had occurred.

Treatment in chronic pyuria should be carried out with careful consideration of all the points in the case. Detection of foci of infection elsewhere and

TABLE 3.

Chronic pyuria cases investigated by urography.

\begin{tabular}{|c|c|c|c|c|c|c|c|c|}
\hline Date & Case No. & Age & Sex & History & $\begin{array}{c}\text { Blood } \\
\text { urea }\end{array}$ & Calvert test & Urogram & Remarks \\
\hline 1930 & 25 & $7 \frac{3}{4}$ & $\mathbf{F}$ & $\begin{array}{l}\text { Pyuria detected } 1929 . \\
\text { Persistent after } \\
\text { medical treatment, } \\
\text { etc. }\end{array}$ & $39 \cdot 0$ & $\begin{array}{l}\text { A } 310 \text { c.cm. } 4 \cdot 8 \% \\
\text { B } 370 \text { c.cm. } 0 \cdot 9 \%\end{array}$ & $\begin{array}{c}\text { Left kidney shows } \\
\text { dilatation of the } \\
\text { renal pelvis with a } \\
\text { small calculus. } \\
\text { Right kidney and } \\
\text { ureter normal. Ex- } \\
\text { cretion rate normal. }\end{array}$ & $\begin{array}{l}\text { Persistent pyuria } \\
\text { associated with } \\
\text { defect in the } \\
\text { left renal tract. }\end{array}$ \\
\hline 1930 & 20 & $4 \frac{1}{4}$ & $\mathbf{M}$ & $\begin{array}{l}\text { Pyuria first detected } \\
\text { in } 1927 \text {-has been } \\
\text { persistent ever } \\
\text { since. }\end{array}$ & $36 \cdot 0$ & $\begin{array}{l}\text { A } 325 \text { c.cm. } 1 \cdot 8 \% \\
\text { B } 110 \text { c.cm. } 2 \cdot 0 \%\end{array}$ & $\begin{array}{l}\text { Both kidneys show } \\
\text { extensive deform- } \\
\text { ity. No calculus. }\end{array}$ & $\begin{array}{c}\text { Persistent pyuria } \\
\text { associated with } \\
\text { bilateral renal } \\
\text { tract deformity. }\end{array}$ \\
\hline 1930 & P. W. & $1 \frac{1}{2}$ & $\mathbf{F}$ & $\begin{array}{l}\text { Pyuria since } 1929 . \\
\text { No response to } \\
\text { treatment. }\end{array}$ & $43 \cdot 0$ & & $\begin{array}{l}\text { Renal shadows both } \\
\text { large and irregular. } \\
\text { No calculus. }\end{array}$ & ditto \\
\hline 1930 & J. L. & 3 & $\mathbf{F}$ & $\begin{array}{l}\text { Pyuria } 6 \text { months. } \\
\text { No response to } \\
\text { treatment. }\end{array}$ & & & $\begin{array}{l}\text { Right side shows a } \\
\text { dilated kidney and } \\
\text { dilated ureter. Left } \\
\text { side normal. }\end{array}$ & $\begin{array}{l}\text { Persistent pyuria } \\
\text { associated with } \\
\text { right renal tract } \\
\text { deformity. }\end{array}$ \\
\hline 1930 & D. C. & $\frac{1}{2}$ & $\mathbf{M}$ & $\begin{array}{l}\text { Pyuria detected age } \\
2 \text { months - per- } \\
\text { sistent. }\end{array}$ & & & $\begin{array}{l}\text { Very dilated left kid- } \\
\text { ney pelvis. Right } \\
\text { appears normal. }\end{array}$ & $\begin{array}{l}\text { Chronic pyuria } \\
\text { and left renal } \\
\text { deformity in an } \\
\text { infant. }\end{array}$ \\
\hline 1930 & 21 & 6 & $\mathbf{F}$ & Pyuria detected 1927. & $30 \cdot 0$ & A 325 c.cm. $3 \cdot 9 \%$ & $\begin{array}{l}\text { Right kidney shows } \\
\text { a marked pelvic } \\
\text { deformity. } \\
\text { and leter } \\
\text { normal. }\end{array}$ & $\begin{array}{l}\text { Chronic pyuria } \\
\text { with right renal } \\
\text { deformity. }\end{array}$ \\
\hline 1930 & L. L. & 9 & $\mathbf{F}$ & $\begin{array}{l}\text { Pyuria with occa- } \\
\text { sional hæmaturia } \\
\text { at least } 18 \text { months. }\end{array}$ & $37 \cdot 0$ & $\begin{array}{l}3 \cdot 9 \% \\
0 \cdot 5 \%\end{array}$ & $\begin{array}{l}\text { Right hydronephrosis } \\
\text { and hydro-ureter. } \\
\text { A calculus present. } \\
\text { Left tract normal. }\end{array}$ & $\begin{array}{l}\text { Chronic pyuria } \\
\text { with right renal } \\
\text { tract deformity } \\
\text { and calculus. }\end{array}$ \\
\hline
\end{tabular}

their eradication is necessary. Most children will show the general effects of chronic sepsis and the physical condition should be improved before any urographic or surgical investigation is made. A full investigation of the renal function is best carried out in children by the urea-concentration method 
of Calvert and the blood-urea estimation. Radiographic investigation for calculus formation and intravenous urography for determining the anatomical outline of the urinary tract is required. Sometimes a cystoscopic examination of the bladder is of use, a diverticulum may be detected or chronic secondary cystitis seen.

Direct treatment of a chronic infection of the renal pelvis and ureter has been carried out in some cases by ureteral catheterization and renal lavage with colloidal silver preparations, but very little improvement has followed. Irrigation of the bladder with antiseptic fluid, or the daily injection of small amounts of weak silver nitrate solution, has not met with any marked success, as might be expected where purulent urine is continually entering the bladder.

Alkalies, hexamine, hexyl-resorcinol,'pyridium,' vaccines and bacteriophage have all proved of very little permanent value in chronic pyuria associated with renal tract deformity.

Reference to Cases 27 and 28 detailed above illustrates the great benefit obtained and complete cure of the pyuria following removal of the diseased lidney. In each child complete recovery has occurred, the urine and renal function are now normal, and the physical condition excellent. It appears, therefore, that the only treatment of permanent value is surgical removal of the diseased part of the renal tract. In patients where the condition is unilateral this can be carried out very satisfactorily, but obviously where bilateral disease exists no such procedure is possible. In the latter cases general medical supervision should be made to preserve the physical condition and general resistance as long as possible, and so delay the occurrence of uræmic toxæmia. Under such conditions the patient may survive for many years, in fact as long as the diminishing functionating kidney tissue lasts, provided that no rapid intercurrent infection of the renal parenchyma takes place.

\section{Discussion.}

Our studies in acute pyuria have yielded considerable information concerning the clinical progress, certain prognostic features and the remote conditions following acute infections of the renal tract. Enquiry has shown that there is no general physical or renal impairment in ony of the patients who rapidly responded to treatment, and complete cure is established in all the patients re-examined from two to five years after the acute illness. This group of cases includes all those who have suffered from acute pyelitis, usually due to B. coli infection.

Broadly speaking, the older the child the less is the probability of any serious involvement of the renal parenchyma. In infants and young children, however, a general spread of the purulent process into the kidney substance may take place and suppurative pyelo-nephritis supervene, whish almost certainly renders the condition an extremely grave cne. In all the fatal cases of acute renal tract infection post-mortem examination has shown this change.

Cases of chronic pyuria, that is where purulent urine occurs over a period 
of months or years, have received special attention, and various methods of investigation have been utilized in order to find the usual reasons for this perpetuation of the infection in the urinary tract. In the first place the remarkably good general condition of many children with chronic pyuria indicates that, in most instances, no serious renal dysfunction exists. Therefore it is highly probable that the infective condition does not directly involve the renal parenchyma. In fact the length of life under these conditions depends upon the absence of spread to the renal secretory tissues. On the contrary, as shown by the clinical records and necropsy examinations, an acute extension of the suppuration to the kidney tissues exists in the fatal cases.

In nearly all cases of chronic suppuration in the renal tract the primary focus of the disease lies in the supra-vesical portion, in the ureter and renal pelvis. Very rarely the chronic infection is due to some abnormality in the bladder such as a congenital diverticulum or urethral mucosal valves producing deficient blodder action, or it is assoziated with disease in the nervous system. Addison ${ }^{2}$ has outlined the clinical features and methods of treatment in cases of congenital valvular urethral obstruction with vesical and ureteral dilatation.

The embryological development and growth of the bladder, ureters and renal pelvis from the cloaca and the ultimate union with the metanephric tissues is a complex process, and it is not surprising that developmental abnormalities should appear in the tract. Congenital polycystic disease is due to intra-renal malformation usually explained as a failure of union between the collecting tubules and secreting tubules. We are concerned here with defective malformations at a lower level. Hyman ${ }^{3}$ notes that the incidence of malformations in the urinary organs is $\mathbf{2} \cdot 3$ per cent. of all post-mortem cxaminations in children, and the greater number occur in the upper part of the tract leading to hydronephrosis and later pyonephrosis. Improper drainage, resulting in stasis and chronic infection, usually brings the patient under observation. The sexes are about equally affected and abnormalities in the genitalia are sometimes present also. Congenital hydronephrosis is one of the commonest varieties, Bugbee ${ }^{4}$ finding 53 cases in 4,000 necropsies. These conditions often remain unrecognized until of palpable size or infection of the part occurs, the latter sometimes remaining symptomless for many months. Dilatation of one or both ureters, sometimes to an extreme degree and involving the whole length or only a segment of the tube may be present, and often the ureteric orifices are gaping or normal in appearance. The pathogenesis of such conditions has not been satisfactorily explained but possibly failure of important neuromuscular connections is present-in fact it may be somewhat comparable to congenital megacolon. Poynton and Sheldon ${ }^{5}$ have given a careful review of some of the clinical and pathological aspects of dilatation of the ureters and bladder and they note the numerous varieties which are seen, some showing definite organic stricture and others not revealing any such cause. It is quite apparent that a great variety of malformations are possible in the renal tract, and many types have been found. In the present discussion the important thing is their realization as a very important factor in chronic urinary infections. Whereas formerly the condition 
was often a necropsy finding, instances are now more frequently recognized as a result of special urological studies in the cases. Systematic physical examination may disclose other congenital defects such as epispadias, hypospadias, atresia ani, spina bifida, etc., and sometimes a unilateral genital defect is present on the same side as a unilateral urinary abnormality.

Two instances of unilateral congenital hydronephrosis are shown in the drawings (Figs. 6 and 7) :-

(a) Male, aged $1 \frac{1}{2}$ years. Died of acute septic meningitis. Never any urinary symptoms and the urine was normal. The left kidney was found to possess a dilated pelvis without ureteral abnormality or obstruction and the right kidney, ureter and the bladder were quite normal (Fig. 6).

(b) Female, aged 2 years. Died of tuberculous meningitis. Never any urinary symptoms and the urine was normal. The right kidney showed a congenital hydronephrosis and no ureteral disease ; the left kidney, ureter and the bladder were normal (Fig. 7).

The principle diagnostic aid in the recognition of defects in the urinary tract are radiographic. The ordinary cystogram or pyelogram may be used but the use of the intravenous uroselectan method is of special value in children. Uroselectan is a neutral, water-soluble, non-toxic organic compound of iodine and pyridine, opaque to $\mathrm{X}$-rays, and which when injected intravenously in 40 per cent. solution is rapidly excreted by the kidneys, and a radiographic outline of the urinary tract is obtained. Fig. 1 shows the normal picture, the renal pelves, ureters and bladder being shown. Radiographs of patients showing renal tract defects are also shown. In Case L.L. an ordinary radiogram showed a calculus in the right kidney pelvis, but urographic examination revealed advanced hydronephrosis and hydro-ureter without ureteric obstruction, the left side being normal (Fig. 4).

This simple method of demonstrating renal tract defect in chronic pyuria is of considerable value in arriving at a complete diagnosis in these cases.

\section{Conclusions.}

1. Clinical studies in a large series of cases of acute pyelitis in children show that although there may be a slight degree of impairment of kidney function in the acute pyrexial stage, there is no permanent or progressive renal damage and complete cure follows medical treatment.

2. Fatal cases of acute purulent renal tract disease in children show suppurative pyelonephritis with considerable destruction of the renal parenchyma.

3. Chronic pyuria is nearly always associated with congenital anatomical defects in the renal tract which impede the normal peristaltic movement and drainage.

4. The use of intravenous uroselectan, enabling urographic examination to show these defects, is of special value in children.

5. The treatment which has proved of permanent value and curative in chronic pyuria associated with renal or ureteral malformation, is excision of the diseased part of the upper renal tract in unilateral cases. In bilateral conditions surgical measures are not possible. 


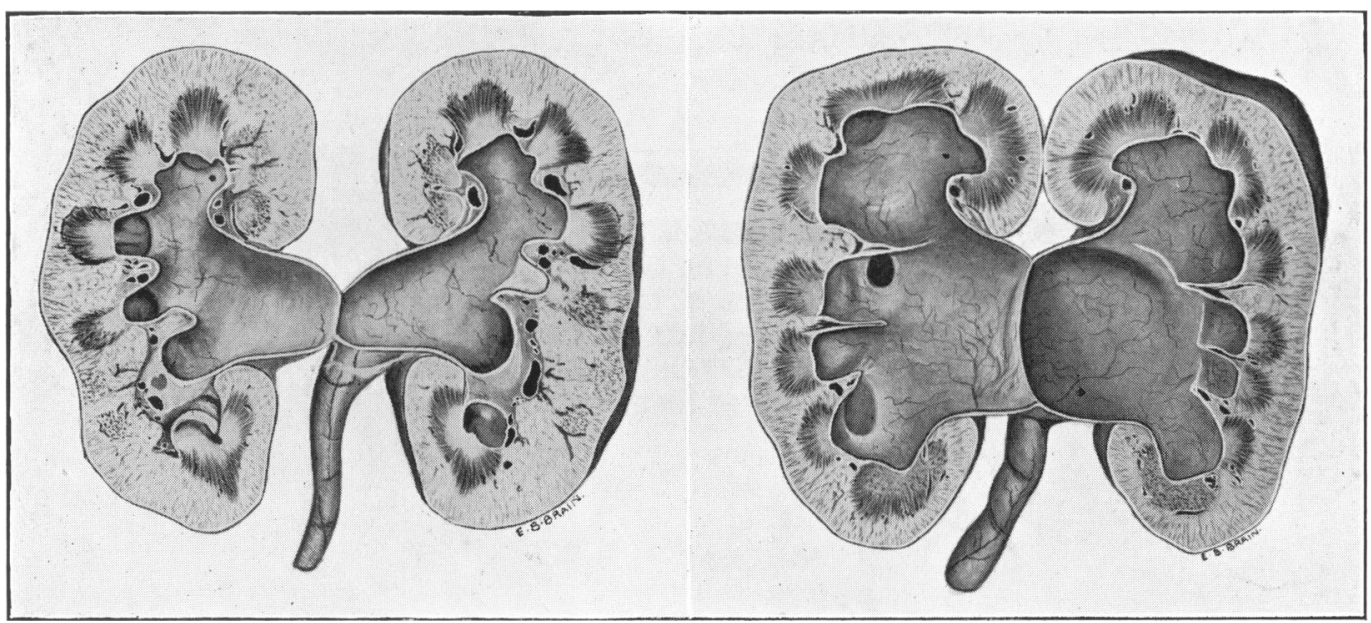

FIg. 6. J. M., male, aged $1 \frac{1}{2}$ years. Died of pneumococcal meningitis. Never any urinary symptoms and urine normal. The left kidney found to have dilated pelvis with normal lower urinary tract. Right kidney and ureter normal. Congenital hydronephrosis.

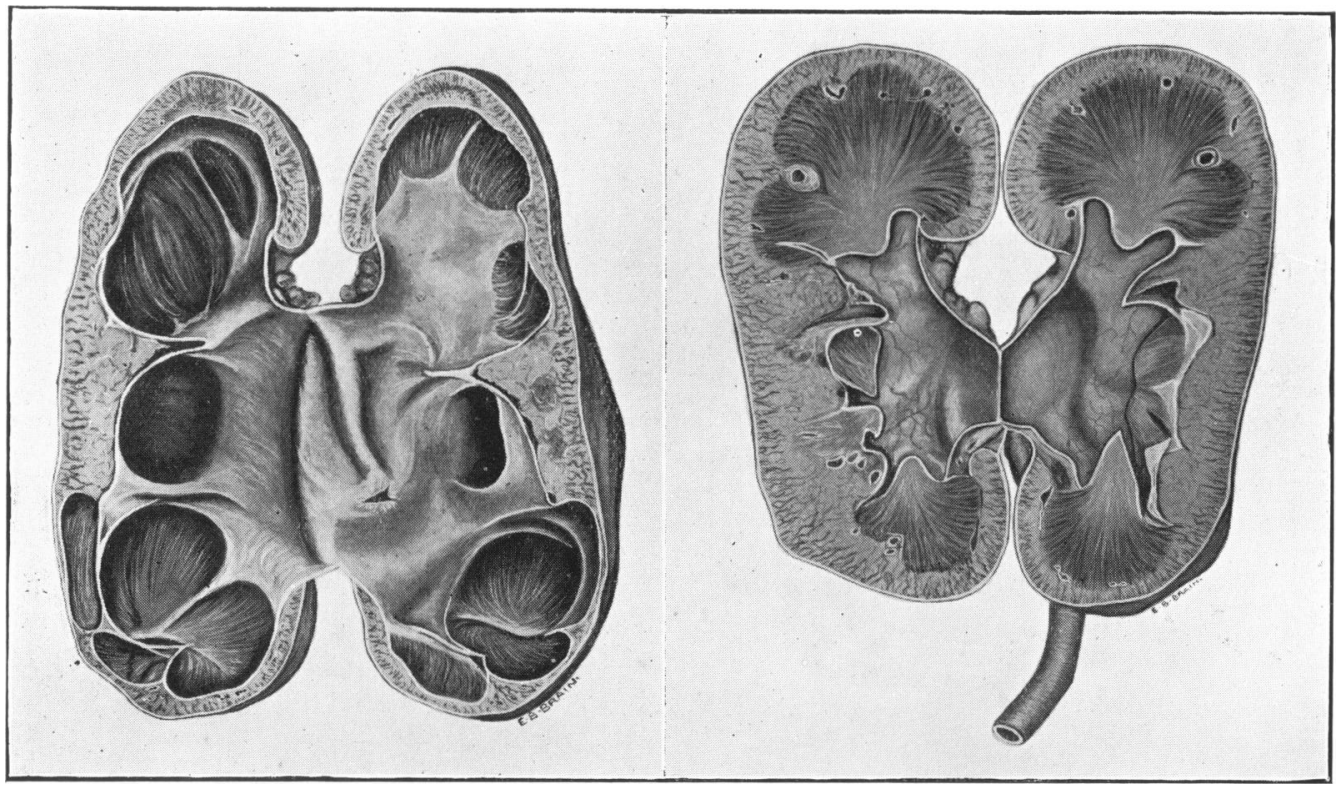

Fic. 7. Juan M., female aged 2 years. Death from tuberculous meningitis. Never any urinary symptoms and urine normal. The right kidney showed a congenital hydronephrosis without any evidence of ureteral obstruction or dilatation. The left kidney and ureter were normal, Bladder and urethra normal. 
I am extremely grateful to the physicians and surgeons of the Children's Hospital, to the radiologists, Dr. Teale and Dr. Thorpe, and to the biochemist, Dr. Hickmans, for collaboration in this work.

\section{REFERENCES.}

1. Wilkinson, K. D., Brit. Med. J., Lond., 1930, ii, 412.

2. Addison, O., Arch. Dis. Childh., Lond., 1929, IV, 255.

3. Hyman, A. B., Dis. Urinary Tract in Children, Lond., 1930.

4. Bugbee, H. G., J. Am. Med. Ass., Chicago, 1924, LXXXIII, 1887.

5. Poynton, F. J., and Sheldon, W. P. H., Idem., 1927, II, 251.

6. Hurst, A. F., Guys Hosp. Rep., Lond., 1930, LXXX, 334. 